\section{Safety of local} anaesthesia for cataract surgery: why we should look again

\author{
Eye (2003) 17, 127-128. doi:10.1038/ \\ sj.eye. 6700393
}

In recent years, there have been major changes in the provision of cataract surgery. More operations are being performed more efficiently, and with better outcomes, than ever before. A mere decade or so ago, most cataract surgery in the UK was performed using large-incision extracapsular techniques, and general anaesthesia was used for over half of all cases. ${ }^{1,2}$ Now, the vast majority of cases are performed using small-incision phacoemulsification techniques ${ }^{3}$ and local anaesthesia (LA). ${ }^{4}$

The emergence of small-incision surgery has been accompanied by a rise in popularity of the less invasive techniques of administering LA, such as sub-Tenon's ${ }^{5}$ and topical anaesthesia. ${ }^{6}$ A 1989 UK survey showed that topical anaesthesia was the preferred technique for $1.4 \%$ of consultant ophthalmologists; the sub-Tenon's technique was yet to be rediscovered. ${ }^{7}$ By 1996, usage of the two techniques had increased to 7 and $3.4 \%$, respectively, ${ }^{8}$ and a 2001 survey indicated $28 \%$ sub-Tenon and $21.5 \%$ topical. ${ }^{4}$ These figures are not strictly comparable due to differences in research methodology, but they do serve to illustrate the major shifts in LA provision over the last few years.

In this rapidly changing field, it is important for us to ensure that we are doing the right thing for our patients. Few would dispute that LA is preferable to general anaesthesia for the majority of cataract patients, ${ }^{9}$ but are we using the best techniques for administering the LA? The ideal LA for cataract surgery would be $100 \%$ effective and $100 \%$ free of risk. Several LA techniques have been introduced as a possible 'ideal LA', but in truth none is perfect. Retrobulbar injections, ${ }^{10}$ the mainstay of ophthalmic LA for much of the 20th century, can cause blindness or brain-stem anaesthesia, which can be life-threatening. ${ }^{11}$ Peribulbar
T Eke $^{1}$ and JR Thompson ${ }^{2}$

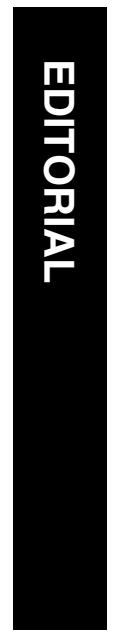

anaesthesia was introduced as a safer alternative, and the initial description ${ }^{12}$ stated that 'complications of retrobulbar anesthesia.... are greatly minimized in peribulbar anesthesia...'. Unfortunately, this has not proved to be the case, as the two techniques have similar incidences of globe perforation and brain-stem depression. ${ }^{11,13}$ Sub-Tenon anaesthesia has now been associated with globe perforation, ${ }^{14}$ and many glaucoma surgeons are concerned that the technique may jeopardise the outcome of future filtering surgery. Topical anaesthesia does avoid the risks of the needle, but some surgeons are unhappy to operate on a potentially mobile eye, and the technique does not block the oculo-cardiac and other reflexes.

So, how can we audit the safety of LA for cataract surgery? Since serious problems are rare, a large sample size is required. This means a study on a national scale, lasting many months. This was last done in the UK in 1996, when the Royal College of Anaesthetists and the Royal College of Ophthalmologists sponsored the National Survey of Local Anaesthesia for Ocular Surgery. ${ }^{8,13}$ This observational study looked at safety aspects of around 65000 LAs which were given over a 3-month period. Sight- and life-threatening complications were reported in around $0.05 \%$ of retrobulbar and peribulbar injections, ${ }^{13}$ although the true figure is probably higher ${ }^{11}$ due to underreporting. There were too few cases performed using sub-Tenon, subconjunctival, topical or topical-intracameral anaesthesia to assess their safety with any degree of certainty. ${ }^{13}$ The safety of these 'newer' LA techniques has not been assessed in any large clinical study. Published series, comprising a few thousand cases each, appear to confirm low complication rates, but case series produced by centres with an interest in LA safety should always be interpreted with caution. For example, the safety profile shown in the initial published series of 16224 peribulbar LAs ${ }^{15}$ has not been

\author{
${ }^{1}$ Norfolk \& Norwich \\ University Hospitals NHS \\ Trust \\ Norwich, UK \\ ${ }^{2}$ Department of Ophthalmic \\ Epidemiology \\ University of Leicester \\ Leicester, UK \\ Correspondence: \\ Mr Tom Eke \\ Department of \\ Ophthalmology \\ Norfolk \& Norwich \\ University Hospitals NHS \\ Trust, Colney Lane \\ Norwich NR4 7UZ, UK \\ Tel: + 441603288578 \\ Fax: + 441603288261 \\ E-mail: tom.eke@ \\ nnuh.nhs.uk
}


replicated in the 'real world'. ${ }^{11}$ As a result of the recent increase in usage of topical and sub-Tenon LA, it is time for this subject to be revisited.

Last autumn, a second national survey of LA safety began. This new survey is carried out by the same investigators as the 1996 survey, with broadly similar study aims and design. This time, the study takes place through the British Ophthalmic Surveillance Unit (BOSU), which was set up to facilitate case ascertainment for studies of rare ophthalmic conditions. BOSU mails a return-addressed postcard to all ophthalmologists of consultant and associate specialist grade in the UK and Eire, enquiring whether they have seen any cases of a limited number of specified conditions in the preceding month. For this study, ophthalmologists are asked to provide details of any case in which a potentially life- or sight-threatening complication occurred after LA was given for cataract surgery. Each case so identified will engender a brief questionnaire, asking what LA technique was used, what happened and what the outcome was. Case ascertainment through BOSU will continue for 1 year. At the midpoint, a questionnaire will be sent to the above ophthalmologists, in order to assess current usage of LA and of the various LA techniques. This study will, therefore, look at the safety of tens of thousands of sub-Tenon, topical and injection LAs, and should be able to give a reasonable idea of their safety in routine clinical practice.

From our knowledge of ocular anatomy and physiology, we would expect that sub-Tenon's or topical LA would be safer than retrobulbar or peribulbar injections. As indicated above, there has been no large study to confirm or refute this presumption. If the current trend towards using these techniques is to continue, it is important to be certain that these LA techniques are at least as safe as their predecessors. The BOSU study will go some way towards answering this question, and the results will be of interest to ophthalmic anaesthetists and cataract surgeons everywhere.

\section{References}

1 Courtney P. The National Cataract Surgery Survey: I. Method and descriptive features. Eye 1992; 6: 487-492.

2 Hodgkins PR, Luff AJ, Morrell AJ, Botchway LT, Featherston TJ, Fielder AR. Current practice of cataract extraction and anaesthesia. Br J Ophthalmol 1992; 76: 323-326.

3 Desai P, Minassian DC, Reidy A. National cataract surgery survey 1997-8: a report of the results of the clinical outcomes. Br J Ophthalmol 1999; 83: 1336-1340.

4 Smerdon D, Kumar C, Dodds C, Welsh A. Current practice in cataract surgery in the UK: results of UKISCRS membership survey. In: Kumar C (ed). British Ophthalmic Anaesthesia Society Third Annual Conference. BOAS: Middlesbrough, 2001, p 58.

5 Stevens JD. A new local anesthesia technique for cataract extraction by one quadrant sub-Tenon's infiltration. $\mathrm{Br} \mathrm{J}$ Ophthalmol 1992; 76: 670-674.

6 Fine IH, Fichman RA, Grabow HR. Clear-corneal Cataract Surgery and Topical Anesthesia. SLACK: Thorofare, NJ, 1993.

7 Campbell DN, Spalton DJ. A national survey of the use of local anesthesia for cataract surgery. Eur J Implant Refract Surg 1992; 4: 213-217.

8 Eke T, Thompson JR. The National Survey of Local Anaesthesia for Ocular Surgery. I. Survey methodology and current practice. Eye 1999; 13: 189-195.

9 Anon. Local Anaesthesia for Intraocular Surgery. Royal College of Anaesthetists, Royal College of Ophthalmologists: London, 2001.

10 Atkinson W. Retrobulbar injection of anesthetic within the muscle cone. Arch Ophthalmol 1936; 16: 494-503.

11 Hamilton RC. Complications of ophthalmic regional anaesthesia. In: Kumar CM, Dodds C, Fanning GL (eds). Ophthalmic Anaesthesia. Swets \& Zeitlinger: Lisse, Netherlands, 2002, pp 181-196.

12 Davis 2nd DB, Mandel MR. Posterior peribulbar anesthesia: an alternative to retrobulbar anesthesia. J Cataract Refract Surg 1986; 12: 182-184.

13 Eke T, Thompson JR. The National Survey of Local Anaesthesia for Ocular Surgery. II. Safety profiles of local anaesthesia techniques. Eye 1999; 13: 196-204.

14 Frieman BJ, Friedberg MA. Globe perforation associated with subtenon's anesthesia. Am J Ophthalmol 2001; 131: 520-521.

15 Davis 2nd DB, Mandel MR. Efficacy and complication rate of 16,224 consecutive peribulbar blocks. A prospective multicenter study [published erratum appears in J Cataract Refract Surg 1994; 20(6): 673]. J Cataract Refract Surg 1994; 20: 327-337. 